\title{
Review of: "Prevalence and factors associated with family planning during COVID-19 pandemic in Bangladesh: A cross-sectional study"
}

Nursel Alp Dal

Potential competing interests: The author(s) declared that no potential competing interests exist.

Dear editor and authors family planning is a very sensitive issue in underdeveloped and developing countries, especially in Muslim countries. It has become even more important during the Covid 19 process. The introductory part of the study is well written and the method part is quite explanatory. In the findings, the researchers compared the demographic characteristics and family planning in Table 1. The relationship was also examined in the regression analysis table. My suggestion is that only demographic characteristics should be given in the table. In the discussion, researchers should interpret the results. It shouldn't just be compared to research. I recently had a study in which I evaluated the family planning attitudes of women in Turkey during the COVID-19 process. In the journal Religion and Health. I recommend that the researcher also benefit from this resource. Because there are rare studies done in this process. Best regards. 